\title{
A VUELTAS CON LAS GARANTÍAS DE LA INDEPENDENCIA JUDICIAL (Comentario a la STS de 13 de junio de 2008)
}

\author{
JORGE ALGUACIL GONZÁLEZ-AURIOLES \\ Profesor Contratado Doctor de Derecho Constitucional \\ UNED
}

\begin{abstract}
SUMARIO
I. Los derechos y bienes constitucionales en conflicto en la sentencia del Tribunal Supremo de 13 de junio de 2008.

II. Los fundamentos de la sentencia.

III. Sobre las garantías de la independencia judicial.
\end{abstract}

Es clásica la afirmación de que ningún derecho o bien constitucional es ilimitado ${ }^{1}$. En nuestra moderna democracia pluralista los derechos y bienes constitucionales se interrelacionan y limitan entre sí. De hecho, el propio constituyente previó explícitamente un supuesto de colisión entre derechos, concretamente, entre la libertad de expresión y el derecho al honor (artículo 20.4 CE): la libertad de expresión encuentra un límite en el necesario respeto al honor, la intimidad, la propia imagen y la protección de la juventud y la infancia. La doctrina, por lo demás, se ha prodigado en analizar el sentido y el alcance de este conflicto entre derechos ${ }^{2}$.

1 Si bien tal afirmación podría imponer ciertas reflexiones sobre el valor de la dignidad de la persona, el derecho a la vida y la prohibición de la tortura, cfr. GuTiérRez GuTiÉrREz, I., Dignidad de la persona y derechos fundamentales, Madrid-Barcelona: Marcial Pons, 2005, págs. 25 y ss.

2 Cfr, a modo de ejemplo, Balaguer Callejón, M.L, El derecho fundamental al honor, Madrid: Tecnos, 1992, Bastida Freijedo, F; Villaverde MenÉndez, I., Libertades de expresión e información y medios de comunicación, Pamplona: Aranzadi, 1998, LóPEz GuERRA, L., "Límites a las libertades de expresión e información. Honor e intimidad", Información y libertades públicas en España, Madrid, 1989, SolozÁbal Echavarría, J. J., "Aspectos constitucionales de la libertad de expresión y el derecho a la información", Revista de Estudios Políticos n. 71. 
Ahora bien, la evolución de nuestro régimen constitucional ha multiplicado los supuestos de colisión entre derechos, por ejemplo entre la misma libertad de expresión y los derechos que dimanan del artículo 24 CE y entre éstos entre sí; lo prueba esta sentencia del Tribunal Supremo que, justo por ello, adquiere una especial significación que la hace merecedora, al menos, de unas breves glosas. Comenzaremos analizando el conflicto planteado en la sentencia, y así los diferentes derechos y bienes constitucionales en liza (1). No interesa tanto el fallo específico de la sentencia, por lo demás fácilmente predectible; importa sobre todo las consideraciones realizadas en sus fundamentos jurídicos, pues a partir de ellas podremos comprender cuándo la libertad de expresión y de actuación de las partes procesales puede afectar a la independencia judicial y cuándo no (2). Esta distinción resulta básica para entender los riesgos reales que tiene el ejercicio de este derecho en la independencia judicial, lo que nos debe llevar a reflexionar sobre la necesidad de alcanzar una interpretación recíprocamente conforme entre estos derechos y bienes constitucionales (3).

\section{LOS DERECHOS Y BIENES CONSTITUCIONALES EN CONFLICTO EN LA SENTENCIA DEL TRIBUNAL SUPREMO DE 13 DE JUNIO DE 2008}

\section{I.1. LOS ANTECEDENTES DE LA SENTENCIA}

La sentencia trae causa del recurso contencioso-administrativo interpuesto por el Procurador D. Jorge Laguna Alonso en nombre y representación de D. Alberto López Jurado contra la resolución del Pleno del Consejo del Poder Judicial, de fecha 15 de septiembre de 2005. Merced a la misma, se concedió amparo por el Consejo General del Poder Judicial a la Juez del Juzgado de Primera Instancia e Instrucción de Vilanova y la Giltrú por entender que las diversas actuaciones realizadas por el Letrado Sr. Lajara Hernández y el Procurador Sr. López Jurado tenían por finalidad la perturbación de la independencia judicial y, consideradas en su conjunto, reunían condiciones objetivas para producir inquietud o perturbación de dicha independencia.

La Juez del Juzgado de Primera Instancia e Instrucción de Vilanova i la Giltrú alegaba que se encontraba sometida a un acoso constante por parte de los afectados. No sólo habían presentado continuas quejas hacia su persona, hasta en tres ocasiones por los mismos hechos en el Decanato de los Juzgados de este Partido, en la Unidad de Atención al Ciudadano y ante el Consejo General del Poder Judicial. Además, con motivo de la celebración del Juicio Ordinario 254/01, el Sr. López Jurado interesa en su nombre y en el de sus compañeros ser excusado de la obligación de comparecer; no alega ninguna razón para tal comportamiento, por lo que la Juez manifestó que no quedaba excusado de su obligación de comparecer. El Sr. Procurador, transcurrida más de una hora desde el inicio del juicio, abandona la Sala sin su permiso. 
Al amparo de lo previsto en el artículo 552 LOPJ procedió a incoar el correspondiente expediente sancionador, al considerar que la actitud referida no sólo suponía un incumplimiento de la Ley Procesal, sino una falta de respeto al Juez. Por su parte, el Sr. López-Jurado presentó un escrito en el que además de solicitar la recusación de la Juez, afirmó su enemistad hacia ella, al tiempo que la intimidó con la presentación de una querella. Alegaba además que la Juez sentía enemistad hacia él y ello lo había hecho público. Ésta se siente amenazada y coaccionada en el legítimo ejercicio de sus funciones; teme que el solo hecho de conducirse bajo la más escrupulosa legalidad le suponga el inicio contra su persona de cualquier actuación; por ello solicita el consabido auxilio del Consejo General del Poder Judicial, que se lo otorga en su reunión de 8 de junio de 2005. Acordó, efectivamente, otorgar el amparo previsto en el artículo 14 LOPJ por entender que las diversas actuaciones del letrado «(...) tienen por finalidad la perturbación de la independencia judicial y, consideradas en su conjunto, reúnen condiciones objetivas para producir inquietud o perturbación de dicha independencia" ${ }^{3}$.

Contra este Acuerdo se interpone el preceptivo recurso de reposición en el que se alega, entre otras $\operatorname{cosas}^{4}$, que el amparo otorgado incide en el legítimo derecho que corresponde al justiciable de ejercitar las acciones legales que estime oportunas. La Comisión Permanente del Consejo General del Poder Judicial, sin embargo, desestima este recurso. Entiende que la aplicación que de la garantía de independencia judicial realiza el artículo 14.1 LOPJ debe ser usada de forma estricta: para aplicar el artículo 14 LOPJ debe haberse producido, objetivamente, una ingerencia indebida en la independencia judicial. Pero no cabe, en su opinión, revocar un Acuerdo del Pleno del Consejo General del Poder Judicial salvo que incurra en manifiesta arbitrariedad o desviación del poder, cuestión que no cabe apreciar en el concreto caso ${ }^{5}$.

3 Acuerdo del Consejo del Poder Judicial de 8 de junio de 2005.

4 El recurrente entiende que ha actuado siempre con absoluta corrección en el trato con la Sra. Juez. Niega, por lo demás, que los actos por él emprendidos puedan integrarse en una estrategia conjunta de acoso al Letrado. En cualquier caso, recuerda que hay una denuncia presentada y que es en ese ámbito en el que debe dilucidarse cualquier responsabilidad

5 Alega, por lo demás, el propio Acuerdo del Pleno del Consejo General del Poder Judicial de 9 de julio de 2001 (recurso n. ${ }^{\circ}$ 62/01) que dispone: "partiendo, pues, de tal presupuesto - competencia exclusiva del Consejo General del Poder Judicial para adoptar la decisión correspondiente- la conclusión que se alcanza no es otra que la de que tal decisión, respetados los elementos reglados del acto administrativo singular y específico que constituye, no es susceptible de fiscalización ni en vía administrativa - a través del recurso que se examina- ni en vía jurisdiccional, de forma que la autoridad — en este caso el Consejo General del Poder Judicial - a la que la Ley confiere la competencia para resolver sobre el amparo solicitado no queda sometida, en lo que constituye su estricta decisión, a la revisión en vía administrativa ni en vía jurisdiccional, salvo que fuese manifiestamente arbitraria o incurriese en desviación del poder". 


\section{I.2. DeRECHOS Y BIENES CONSTITUCIONALES EN LIZA}

La resolución del Consejo General del Poder Judicial recurrida ante el Tribunal Supremo parece afectar, en primer lugar, a la libertad de expresión de los recurrentes. Esta libertad, por lo demás, se encuentra íntimamente relacionada con la serie de derechos que el artículo 24 CE otorga al justiciable ${ }^{6}$. En efecto, para hacer real el primero de los derechos que derivan de este articulo, el derecho a la tutela judicial efectiva, no basta con que haya un acceso sin restricciones a la jurisdicción; es necesario, además, y por lo que a nosotros interesa, que no se produzca indefensión. Este derecho, consagrado expresamente en el precepto constitucional, consiste en prohibir que se limite por causa no imputable al justiciable cualesquiera medios legítimos de defensa, entre ellos, claro está, la expresión pública de un desacuerdo y una queja hacia una persona, en este caso, un juez. La censura de esta actuación es lo que se denuncia ante el Tribunal Supremo: la resolución del Pleno del Consejo del Poder Judicial, de fecha 15 de septiembre de 2005, supone en definitiva el reproche a unas actuaciones que el recurrente entiende que forman parte de su defensa.

Por otra parte, del derecho a un proceso justo con todas las garantías, del apartado segundo del artículo 24, cabe extraer el derecho a la imparcialidad del juez, que se proyecta en la garantía de independencia judicial predicada en el artículo 117.1 CE. Este derecho del justiciable, que se convierte en deber de la judicatura, goza en buena lógica de garantías; justo las que invoca la juez del Juzgado de Primera Instancia e Instrucción de Vilanova i la Giltrú y cuyo otorgamiento provoca el recurso.

Nos encontramos, pues, ante el conflicto entre el ejercicio de dos derechos por parte del justiciable, la libertad de expresión (artículo 20.1 a CE) y el derecho de acceso a la jurisdicción, tal y como ha sido interpretado por el Tribunal Constitucional (artículo 24.1 CE), de un lado; y, del otro, el derecho que se deriva de la garantía genérica de acceso a un proceso público sin dilaciones indebidas y con todas las garantías (artículo $24.2 \mathrm{CE}$ ), el derecho a la imparcialidad del juez, que a su vez deviene en la garantía de independencia judicial predicada en el artículo 117.1 CE.

\section{LOS FUNDAMENTOS DE LA SENTENCIA}

Como hemos observado anteriormente, no interesa tanto el fallo de la sentencia, sino las consideraciones que realiza el Tribunal sobre la pertinencia

6 Así, del artículo 24 CE cabe extraer cuatro grupos de derechos, el derecho de acceso a los tribunales, el derecho al juez predeterminado por la ley, las garantías constitucionales genéricas de todo proceso, y las garantías constitucionales específicas del proceso penal, DíEz-PicAzo y PONCE DE LEÓN, L., "Notas sobre el derecho a la tutela judicial efectiva", Poder Judicial n. ${ }^{\circ}$ 5, DíEz-PICAZo Giménez, L. M., Sistema de derechos fundamentales, Madrid: Civitas, 2003, págs. 363 y ss. 
de la aplicación del artículo 14 LOPJ, precepto tendente a proteger al juez en su independencia. Afirma en primer lugar que la Constitución no sólo contempla la independencia del Poder Judicial respecto de otros poderes del Estado, también lo realiza respecto de sus propios órganos de gobierno. Acto seguido destaca la importancia de esta independencia, que entronca históricamente con la doctrina de la separación de poderes, y que se configura en eje central de la regulación de la Ley Orgánica del Poder Judicial. El contrapeso de esta independencia, de sobra conocido, es la responsabilidad y el estricto sometimiento de los jueces y magistrados en su función jurisdiccional al imperio de la ley (artículo $117 \mathrm{CE}$ ).

El mencionado artículo 14 LOPJ dispone en su apartado primero: "Los Jueces y Magistrados que se consideren inquietados o perturbados en su independencia lo pondrán en conocimiento del Consejo General del Poder Judicial, dando cuenta de los hechos al Juez o Tribunal competente para seguir el procedimiento adecuado, sin perjuicio de practicar por sí mismos las diligencias estrictamente indispensables para asegurar la acción de la justicia y restaurar el orden jurídico". Merced a su apartado segundo, "El Ministerio Fiscal, por sí o a petición de aquéllos, promoverá las acciones pertinentes en defensa de la independencia judicial".

Pero la aplicación de este precepto exige, en opinión del Alto Tribunal, "que haya habido, objetivamente, una injerencia indebida en la independencia judicial (...) No está pensado para la defensa del Juez dentro de la relación procesal, donde el ordenamiento le habilita de potestad disciplinaria en relación con los intervinientes en el proceso, como la posibilidad de deducir testimonio de las actuaciones que considera pudieran revestir carácter penal". Y así, como no podía ser de otro modo, la sentencia del Tribunal Supremo estima el recurso contencioso-administrativo: la juez no sólo había abierto expediente disciplinario al recurrente, sino que los hechos habían sido comunicados al Ministerio Fiscal, por lo que, como manifiesta el Alto Tribunal, "con independencia de que la misma pudiera considerar subjetivamente que se le estaba presionando por las partes, ni estos hechos se habían convertido objetivamente en un ataque a la independencia judicial, objetivamente considerados, ni habían trascendido a la opinión pública general, ni eran extraños a las partes que intervenían en el proceso, por lo que la actuación del Consejo General era innecesaria». Las actuaciones de los recurrentes en ningún caso podían alterar la independencia de un juez que dispone de medios para hacer frente a conductas que alteran el buen orden del proceso: el juez goza de capacidad disciplinaria para hacer frente a tales hechos. No tiene sentido, pues, la aplicación del artículo 14 LOPJ.

Interesa saber, por el contrario, cuándo puede ser el juez perturbado en su independencia y así ser pertinente la aplicación del mencionado artículo. $\mathrm{Y}$ es aquí donde entra en juego un nuevo valor hasta ahora no tenido en cuenta: la relevancia pública de las actuaciones de las partes y, en concreto, la capacidad de éstas de acceso y dirección de los medios de comunicación social. Porque, como observa Cámara Villar, "el hasta hacía poco tiempo vi- 
gente y viejo paradigma liberal de la relación entre medios de comunicación y jurisdicción (bien que fuere de manera imperfecta) ha entrado en profunda crisis " ${ }^{7}$. La capacidad de los medios de influir en la opinión pública es cada vez mayor; las posibilidades que pueden tener los justiciables de, haciendo uso de su libertad de expresión, incidir en estos medios de comunicación en un sentido determinado, influir con ello en la opinión pública y llegar así a perturbar la independencia judicial, son cada vez más grandes. La garantía, en opinión del tribunal, adquiere (así) su sentido cuando determinadas actuaciones extrañas a la relación procesal pretenden influir en la opinión pública descalificando al Juez o Tribunal, dudando de su imparcialidad, o presionándoles para que resuelva en un determinado sentido un litigio en curso (...) Justo porque en este caso la "necesaria imparcialidad del juez hace que no pueda contradecir ni matizar personalmente informaciones alrededor de un proceso o litigio cuya resolución le corresponde.. En tales circunstancias, sí parece razonable "que quien tiene atribuido el mandato constitucional de velar por la independencia del Poder Judicial, supla, sin necesidad de entrar en el fondo de la relación litigiosa, aquella defensa que el Juez por si mismo no puede hacer".

Por lo demás, en opinión del Alto Tribunal, para aplicar este precepto han de concurrir no sólo una apreciación subjetiva, sino algunos elementos objetivos "que den visos de verosimilitud a la pretensión de terceros de inquietarle o perturbarle.. Y la experiencia generada desde 1985, pone de relieve que esto únicamente se produce cuando "son las declaraciones y manifestaciones de personas relevantes-bien titulares de cargos públicos, bien dirigentes de organizaciones o entidades privadas relevantes- hechas en público y recogidas en los medios de comunicación, descalificando actuaciones judiciales o al propio Juez (...) También se encuentra en las afirmaciones del mismo o parecido tenor lanzadas desde los propios medios, mediante editoriales, columnas o comentarios, que reflejan puntos de vista del mismo medio y que, simplemente, se dirigen a cuestionar la decisión del juez".

\section{SOBRE LAS GARANTÍAS DE LA INDEPENDENCIA JUDICIAL}

En definitiva, las actuaciones de los justiciables, consistentes en el ejercicio de su libertad de expresión, pueden entrar en colisión con la garantía de la independencia judicial cuando se proyectan en medios de comunicación social de masas; que pueden a su vez llegar a formar una opinión pública susceptible de incidir en la independencia y neutralidad judicial. Si los «medios de comunicación social ya no son tan sólo la expresión del más clásico

7 Cámara Villar, G., "Juicios paralelos y Constitución", Constitución y democracia. 25 años de Constitución democrática en España. Actas del Congreso celebrado en Bilbao los dias 19 a 21 de noviembre de 2003. Volumen 1, Bilbao: Centro de Estudios Políticos y Constitucionales, 2005, pág. 254. 
contrapoder, sino que se han convertido ellos mismos en un nuevo poder ${ }^{8}$, pueden incidir en la garantía de independencia judicial y así en el propio derecho consagrado en el artículo $24 \mathrm{CE}$; se impone entonces algún tipo de regulación que permita ponderar los bienes constitucionales en liza. Porque, en definitiva, como observa Cámara Villar, la "Administración de Justicia y la opinión pública, cuando el derecho a la información se ejerce tan solo desde paradigmas liberales que reivindican el mercado libre de las ideas y de los datos sobre los que se informa, pueden verse así altamente tensionadas por los medios. Con ello existe un elevadísimo riesgo de que en ciertas circunstancias, una vez influida y conformada la opinión pública en una determinada dirección, se puedan ver conculcadas por esta fuerza extraordinaria las garantías jurídicas y ciertos derechos fundamentales" ".

En la sentencia comentada, en definitiva, se propone la posibilidad de limitar la libertad de expresión de los litigantes para asegurar la independencia judicial. Tal límite se articularía mediante la puesta en práctica del artículo 14 LOPJ, pero cabe también pensar en otros medios quizá más gravosos con el derecho fundamental, necesarios, en su caso, para asegurar la independencia judicial; el principio de proporcionalidad debería jugar un papel central en la determinación de la adecuación constitucional de la limitación del derecho. No debemos olvidar, por lo demás, que nos encontramos con la limitación de un derecho fundamental, la libertad de expresión, que debe gozar de las mayores garantías en un Estado democrático; y que en este caso además se une al derecho de defensa del justiciable derivado del artículo $24 \mathrm{CE}$, por lo que cobra un valor aún mayor; es clásica en ese sentido la afirmación de que lo fundamental en todo proceso judicial es garantizar la efectividad de los derechos fundamentales de las partes y, especialmente, del inculpado. Justo el que se restringe en este caso $^{10}$.

El Tribunal Constitucional, ya en su temprana STC 6/1996, se mostró en principio a favor de la libertad de expresión e información, si bien a condición de que los programas en que se difundieran informaciones u opiniones sobre procesos judiciales en curso satisficieran el requisito de la veracidad informativa (STC 6/1996). Sin embargo, esta preferencia casi incondicionada, se matiza en la decisiva a estos efectos STC 136/1999, de 20 de julio, sobre el encarcelamiento de la Mesa Nacional de Herri Batasuna. En opinión del máximo intérprete constitucional, "la protección frente a declaraciones en los medios de comunicación acerca de procesos en curso y frente a juicios paralelos se

8 Cámara Villar, G, "Juicios paralelos y Constitución", op. cit., pág. 255.

9 Camara Villar, G, "Juicios paralelos y Constitución", op. cit., pág. 256.

$10 \mathrm{Y}$ es justo aquí donde encontramos la diferencia fundamental del supuesto que estamos analizando con algunos análisis que se han realizado de los denominados "juicios paralelos". Porque en estos estudios se parte siempre de que el juicio paralelo daña la presunción de inocencia del justiciable y de forma accidental también su derecho al honor (en este sentido, Cámara Villar, G, "Juicios paralelos y Constitución", op. cit., pág. 263). Aquí el valor perjudicado es la propia independencia judicial; los derechos del justiciable, en su caso, son los derechos susceptibles de una eventual limitación. 
debe a que éstos no sólo pueden influir en el prestigio de los Tribunales, sino muy especialmente, y esto es aquí lo relevante, a que pueden llegar a menoscabar, según sea su tenor, finalidad y contexto, la imparcialidad o la apariencia de imparcialidad de los Jueces y Tribunales, ya que la publicación de supuestos o reales estados de opinión pública sobre el proceso y el fallo puede influir en la decisión que deben abordar los Jueces, al tiempo que puede hacer llegar al proceso informaciones sobre los hechos que no están depuradas por las garantías que ofrecen los cauces procesales ${ }^{11}$. Si bien el Tribunal Constitucional no extrae consecuencias de estas consideraciones, pues entiende en definitiva que las declaraciones producidas no han influido en la imparcialidad del tribunal, sienta las bases para poder limitar estas declaraciones a medios de comunicación. En idéntico sentido se pronuncian las SSTC 64/65 y 66/2001.

Así las cosas, cabe plantearse a renglón seguido, a quién compete la tarea de realizar tal delimitación del derecho. Pues bien, no cabe duda que en un Estado social y democrático de Derecho como el nuestro, es al legislador al que le está encomendada la misión; el Tribunal Constitucional habrá de controlar al legislador mediante técnicas como la proporcionalidad ${ }^{12}$. Y así, parece necesaria una regulación legal, como la que reivindica el propio Cámara Villar al abordar los problemas constitucionales que producen los juicios paralelos ${ }^{13}$, y una aplicación más sistemática por parte del Tribunal Constitucional de técnicas como la proporcionalidad que permiten controlar al legislador, a los jueces y a la Administración, la limitación del derecho en cuestión.

En definitiva, la posibilidad de limitar la libertad de expresión en la sentencia comentada se proyecta en la aplicación del artículo de la Ley Orgánica del Poder Judicial, pero caben otras muchas, que habrán de ser reguladas mediante ley, cuya constitucionalidad siempre podrá ser controlada por el Tribunal Constitucional, aplicando de forma más depurada principios como la proporcionalidad. Porque lo cierto es que puede haber casos en que sea necesario amparar al juez y censurar una actuación informativa que en supuestos puntuales deba ceder para asegurar un valor esencial del Estado de Derecho, la independencia judicial, requisito imprescindible para asegurar la tutela judicial efectiva.

11 STC 136/1999, FJ.

12 Sobre la proporcionalidad, cfr. Bernal Pulido, C., El principio de proporcionalidad y los derechos fundamentales, Madrid: Centro de Estudios Políticos y Constitucionales, 2003, LOPERA Mesa, G. P., El principio de proporcionalidad y el legislador penal, Madrid: Centro de Estudios Políticos y Constitucionales, 2003. Entre estos dos autores se ha producido una polémica sobre el uso más extenso o menos extenso del principio, con una evidente repercusión en el papel del legislador en la determinación de la ponderación entre derechos, cfr. al respecto, ALGUACIL GonZÁLEZ-AurIOLES, J., "La proporcionalidad y el principio democrático: presupuestos e implicaciones de un debate constitucional", Revista de las Cortes Generales n. ${ }^{\circ}$ 68, 2006.

13 Cámara Villar, G., "Juicios paralelos y Constitución”, op. cit., pág. 273. 
TITLE: Again about judicial independence guarantees. (Commentary to the Judgment of the Supreme Court dated 13 th. June 2008).

ABSTRACT: The decision of the Supreme Court from 13 June 2008 shows the conflict between the judicial independence and the freedom of speech, freedom that in this case is well-connected with the right of access to the Court, as the Constitutional Court has interpreted. To be exact, the Supreme Court explains the correct application of article 14 LOPJ.

RESUMEN: La resolución del Tribunal Supremo de 13 de junio de 2008 evidencia el conflicto que puede existir entre la independencia judicial y la libertad de expresión, $l i$ bertad intimamente relacionada en el caso en cuestión con el derecho de acceso a la jurisdicción, tal y como ha sido interpretado por el Tribunal Constitucional. En concreto, el Tribunal Supremo explica la aplicación correcta del artículo 14 LOPJ.

KEY WORDS: Judiciary independence. Right to justice. Due process of law. efectiva.

Palabras Clave: Independencia judicial. Acceso a la jurisdicción.Tutela judicial 